\title{
O MAPEAMENTO DA PRODUÇÃO CIENTÍFICA SOBRE PROJETOS ESPORTIVOS NO BRASIL
}

Recebido em: 16/08/2017

Aceito em: 02/04/2018

\author{
Ana Elisa Guginski Caron ${ }^{1}$ \\ Wanderley Marchi Junior ${ }^{2}$ \\ Marcelo Moraes e Silva ${ }^{3}$ \\ Curitiba - PR - Brasil
}

Universidade Federal do Paraná (UFPR)

RESUMO: O presente estudo busca mapear a produção científica brasileira na área de projetos esportivos, visando oferecer um panorama do conhecimento produzido nessa temática para auxiliar na discussão sobre a utilização do esporte em projetos sociais. As pesquisas foram realizadas no Portal de Periódicos da CAPES, no Portal Regional da Biblioteca Virtual em Saúde (BVS) e no Scielo. Foram encontrados 29 artigos, 9 dissertações de mestrado e 2 teses de doutorado sobre a temática com produções que datam de 2003 a 2016. A título de conclusão o estudo aponta que se trata de uma temática com um grande espectro de abordagens e temáticas.

PALAVRAS CHAVE: Atividades Científicas e Tecnológicas. Esportes. Projetos. Atividades de Lazer.

\section{MAPPING THE CIENTIFIC PRODUTION ON SPORTS PROJECTS IN BRAZIL}

ABSTRACT: The present study seeks to map the Brazilian scientific production on sports projects area, in order to draw an overview of produced knowledge in this issue, helping discussions about using sports on social projects. The researches were carried out in the Portal de Periódicos da CAPES, Biblioteca Virtual em Saúde (BVS) and Scielo. As a results of the researches were found 29 articles, 9 master's dissertation and 2 doctoral theses about this issue dating from 2003 to 2016. In conclusion, this study points out this is an issue with wide range of approaches and themes.

KEYWORDS: Scientific and Technical Activities. Sports. Projects. Leisure Activities.

\footnotetext{
${ }^{1}$ Mestranda em Educação Física pela Universidade Federal do Paraná.

${ }^{2}$ Pós-Doutorado em Sociologia do Esporte pela West Virgínia University/USA em 2012. Atualmente professor associado da Universidade Federal do Paraná.

${ }^{3}$ Pós-Doutorado em Educação Física pela Universidade Federal do Paraná. Atualmente professor adjunto do Departamento de Educação Física da Universidade Federal do Paraná.
} 


\section{Introdução}

A produção científica sobre o esporte enquanto um fenômeno social, conforme lembra Paes (2006) está cada vez mais difundida em outras áreas do conhecimento como engenharia, pedagogia, medicina, sociologia, filosofia, entre outras. Estas áreas estão rompendo as barreiras disciplinares tradicionais e tomando o esporte enquanto objeto de estudo. Essa expansão nas possibilidades de produção de estudos se deve a uma ressignificação do esporte enquanto um fenômeno polissêmico e polimórfico (BENTO, 2013), que confere formas, significados e objetivos diferenciados, e suscita a necessidade de conhecimentos para as suas implicações em disciplinas acadêmicas variadas.

$\mathrm{Na}$ esteira desses diferentes significados e objetivos podemos focar o olhar no esporte como uma ferramenta para contribuir para o desenvolvimento de indivíduos e comunidades. Aos benefícios da prática esportiva para a saúde e o bem-estar dos indivíduos são acrescentadas a outras finalidades, principalmente elevando sua potencialidade de reduzir alguns problemas sociais como violência, pobreza, desemprego e também para melhorar a educação (KIDD, 2008; LEVERMORE, 2008; REVERDITO, et al. 2016; MORAES et al. 2017).

No Brasil, a partir da década de 1980, o esporte passa também a se apresentar com um cunho educacional forte, sendo uma alternativa e complementação para a educação formal, tentando suprir as deficiências então apresentadas pelo sistema educacional público e como uma alternativa de ocupação do tempo livre de crianças e jovens nas periferias brasileiras. (ZALUAR, 1994; STIGGER; THOMASSIM, 2013; CORRÊA et al. 2014). Entretanto, Souza; Castro e Mezzadri (2012), indicam que essas iniciativas ainda eram tímidas e embasadas em ações de filantropia de algumas 
empresas, fundações e/ou igrejas. Na opinião dos autores foi somente a partir da década de 1990 que aconteceu um maior desenvolvimento de ações financiadas por organizações não governamentais (ONGs), instituições e fundações que utilizam o esporte como forma de educação e socialização. Essas ações são chamadas de "projetos sociais".

O esporte se apresenta nesses projetos sociais como uma forma de resolver vários problemas sociais que não são enfrentados pelo poder público, indo desde problemas na educação formal, passando por retirar as crianças da rua até o desenvolvimento de renda para as comunidades. O escopo de ações e objetivos dos projetos sociais que utilizam o esporte como meio é tão amplo que suscitam questionamentos sobre a possibilidade de somente a prática esportiva dar conta desses complexos problemas sociais. Seguindo esse raciocínio de confiança extrema nas possibilidades da prática esportiva, Coalter (2013) e Coakley (2015a) afirmam que o pensamento mais correto consideraria o esporte como uma das partes para a resolução dos problemas e não como a única possibilidade para esses problemas.

A utilização da prática esportiva como ferramenta para diminuição de diferentes desigualdades sociais existentes no Brasil é reflexo de uma política social que envolve a participação do Estado e do Terceiro Setor e também do difundido mito que o esporte é inerentemente puro e bom. A simples prática esportiva, conforme aponta Coakley (2014), garantiria ao praticante o aprendizado de somente atributos positivos, não limitando esses benefícios aos indivíduos, mas expandindo suas utilidades para o desenvolvimento de comunidades. Entretanto, é necessário considerar que o esporte é um fenômeno social, sendo influenciado por diferentes esferas da sociedade. Ele 
incorpora elementos de dimensões culturais, econômicas e sociais, que se fazem presentes nas ações educacionais propostas por meio da sua prática.

Stigger e Thomassim (2013, p. 9), ao estudarem o uso de esporte em projetos sociais, seguem a mesma linha de pensamento apontada por Coakley, ao afirmar a "reificação" do esporte, tratando-o como independente da vontade humana.

[...], através do discurso acadêmico, midiático ou do senso comum, interpreta-se aquilo que são os sentidos atribuídos ao esporte pelos agentes de determinados contextos históricos e sociais (praticantes, treinadores, dirigentes, políticos, etc.), como se fossem atributos próprios e naturais do esporte. Numa caricatura dessa visão, o esporte passa a ser compreendido como um ente, acima das relações que as pessoas estabelecem, portador de uma essência que independeria de contexto históricos e culturais e, portanto, dos sentidos que os sujeitos lhe conferem.

Esse poder "mágico" que perpassa o inconsciente coletivo, dominando o senso comum, dificulta discussões críticas, porque se acredita que o esporte não precisa de questionamentos ou aprimoramentos, ou seja, o esporte é perfeito. Essa crença é alimentada por interesses pessoais e políticos (COAKLEY, 2015b).

Devido a essa polissemia que a práticas esportivas podem apresentar, torna-se uma tarefa árdua a produção de conhecimento sobre projetos esportivos sociais, visto que envolvem diferentes formas de trabalho, com objetivos e linhas filosóficas e epistemológicas distintas. Entretanto para aprofundar a discussão sobre o tema, esse artigo objetiva mapear a produção científica brasileira na área de projetos esportivos, visando oferecer um panorama inicial do que já foi produzido para auxiliar na discussão sobre a utilização do esporte como elemento educacional dentro dos projetos sociais.

Bailey (2005) em estudo sobre a relação entre inclusão social e a participação em esporte e Educação Física afirma que existe uma falta de pesquisas sobre essa temática. Dessa forma, um mapeamento inicial do que já foi produzido se justifica por 
ser um marco inicial de investigação da área, auxiliando no aprofundamento para futuras pesquisas.

\section{Metodologia}

O presente estudo tem por objetivo mapear a produção científica brasileira na área de projetos esportivos. Acredita-se que esta abordagem de mapeamento do que foi produzido insere-se na classificação de pesquisas sobre "estado da arte". Esse tipo de pesquisa pode auxiliar na construção de um campo teórico sobre determinado tema, examinando as ênfases e temas mais abordados, os referenciais teóricos utilizados, as tendências de pesquisa e lacunas da área estudada (ROMANOWSKI; ENS, 2006).

Os termos utilizados como critério de busca no Portal de Periódicos da Coordenação de Aperfeiçoamento do Pessoal do Nível Superior (Capes) ${ }^{4}$, Scientific Eletronic Library Online (Scielo) $)^{5}$ e no Portal Regional da Biblioteca Virtual em Saúde $(B V S)^{6}$ foram os seguintes: "projeto esportivo"; "projetos esportivos"; "projeto social esportivo"; "projetos sociais esportivos"; "projetos socioesportivos". Esses portais foram escolhidos por apresentarem em seu acervo acesso a diversas bases de dados que reúnem diferentes trabalhos científicos e acadêmicos. O Portal de Periódicos da CAPES e o Scielo são amplos e não tem área específica, enquanto o Portal Regional da BVS tem seu foco para a área da saúde.

Foram considerados como pertinentes para as análises do presente estudo os resultados da busca nos portais já enunciados que continham em seu título, resumo e/ou palavra chaves os termos definidos acima. Como o objetivo do artigo é trazer o

\footnotetext{
${ }^{4}$ Disponível em: http://www.periodicos.capes.gov.br. Acessado em: 25/05/2017.

${ }^{5}$ Disponível em: http://www.scielo.org/php/index.php?lang=pt. Acessado em: 25/05/2017

${ }^{6}$ Disponível em: http://bvsalud.org/. Acessado em: 26/05/2017.
} 
mapeamento sobre projetos esportivos, a busca não limitou-se somente a artigos, mas incluiu também dissertações de mestrado e teses de doutorado.

Textos em português e publicações em periódicos brasileiros foram utilizados como filtro para as buscas, apresentando assim a realidade da produção científica na área de projetos esportivos no Brasil. Foram selecionados todos os resultados até o ano de 2016, porém sem definição de um recorte temporal inicial, buscando identificar as primeiras publicações e se houveram alterações nos padrões de publicações durante os anos. A busca foi realizada no período de 22 a 26 de maio de 2017 e trouxeram 40 resultados sobre a temática de projetos esportivos sendo 29 artigos publicados em periódicos, 9 dissertações de mestrado e 2 teses de doutorado.

Utilizou da análise de conteúdo de Bardin (1977) para categorizar os objetivos de cada um dos artigos, teses e dissertações. Sá-Silva; Almeida; Guindani (2009, p.11) apresentam a análise de conteúdo de Bardin como uma forma de "[...] relacionar a frequência da citação de alguns temas, palavras ou ideias em um texto para medir o peso relativo atribuído a um determinado assunto pelo seu autor". A categorização dos materiais estudados a partir dos seus objetivos possibilitou compreender com mais profundidade qual área dentro dos projetos esportivos está sendo mais estudada. Cada artigo, dissertação e tese foram inseridos em somente uma categoria, em que representava o maior foco do estudo realizado, mesmo que as discussões apresentadas englobassem outras categorias como suporte para os objetivos principais. As categorias utilizadas para classificar os artigos foram construídas a posteriori após a leitura de seus respectivos resumos e são as seguintes: 
- Gestão: indicadores de frequência, evasão, ocupação, adesão, rotatividade, crescimento de projetos.

- Mudança de comportamento: desempenho escolar, aprendizagem de valores, socialização, redução de ansiedade, respeito às regras.

- Prática Pedagógica: orientações metodológicas, escolha de conteúdos, formas de intervenções.

- Políticas Públicas: direito ao esporte e lazer, políticas sociais, distribuição geográfica de projetos sociais, comunidades, inclusão social.

- Responsabilidade social: terceiro setor, iniciativa privada, patrocínio, trabalho voluntário.

- Saúde: composição corporal, desenvolvimento motor, comportamentos de risco a saúde, desenvolvimento de indicadores de avaliação em saúde.

- Significados e percepções: significados, sentidos e percepções sobre a participação em projetos esportivos por diferentes públicos envolvidos como pais, alunos, professores.

As dissertações e teses foram também classificadas de acordo com a área de conhecimento do curso de pós-graduação aonde foram produzidas. Essas classificações permitem que este estudo avalie sob qual vertente epistemológica vem sendo produzido conhecimento sobre projetos esportivos, permitindo a articulação de análises para o auxílio na compreensão da utilização do esporte como ferramenta de educação dentro da sociedade brasileira. 
Os periódicos em que os artigos foram publicados também foram classificados de acordo com o Qualis $^{7}$ da área 21, que engloba as áreas de Educação Física, Fisioterapia, Fonoaudiologia e Terapia Ocupacional, do ano de 2017.

Um estudo das técnicas de pesquisa utilizadas pelos autores dos artigos, dissertações e teses estudados nesses artigos também foi realizado. Lakatos e Marconi (2003, p. 175) definem técnica como “[...] conjunto de preceitos ou processos de que se serve uma ciência ou arte; é a habilidade para usar esses preceitos ou normas, a parte prática. Toda ciência utiliza inúmeras técnicas na obtenção de seus propósitos”. Foram levantadas todas as técnicas de pesquisa utilizadas pelos materiais estudados nesse artigo. Torna-se necessário pontuar que alguns materiais utilizaram mais de uma técnica de pesquisa para atingir os objetivos propostos.

\section{Resultados e Discussão}

Inicia-se o mapeamento situando temporalmente o material analisado. A Tabela 1 apresenta os anos em que os artigos, dissertações e/ou teses foram produzidos. Apesar de não se ter utilizado nenhum critério para definição do período inicial das publicações, o primeiro registro encontrado foi do ano de 2003, com apenas um artigo publicado. O resultado da busca mostrou que em 2009 aconteceu a defesa da primeira tese de doutorado dentro da temática pesquisada. Foi possível observar que entre 2009 e 2012 se mantem constante o número de publicações, sempre com a produção de dissertações de mestrado. A partir de 2013 até 2016 houve um período grande sem estudos de mestrado ou doutorado relacionados à temática de projetos esportivos.

\footnotetext{
${ }^{7}$ O Qualis é um sistema de classificação de artigos científicos publicados em periódicos. Os periódicos são enquadrados em estratos indicativos de qualidade sendo A1 o mais elevado, passando para A2, B1, B2, B3, B4, B5 e C. Os periódicos são avaliados anualmente pela CAPES (SAMPAIO, 2014).
} 
Tabela 1. Distribuição no recorte temporal - Sistematizado pelos autores.

\begin{tabular}{cccccc}
\hline $\begin{array}{c}\text { Ano/ Tipo de } \\
\text { publicação }\end{array}$ & Artigo & Dissertação & Tese & Total & \% Total \\
\hline 2003 & 1 & & & 1 & $2,5 \%$ \\
2006 & & 1 & & 1 & $2,5 \%$ \\
2007 & 1 & & & 1 & $2,5 \%$ \\
2008 & & 2 & & 2 & $5,0 \%$ \\
2009 & 2 & 1 & 1 & 4 & $10,0 \%$ \\
2010 & 2 & 2 & & 4 & $10,0 \%$ \\
2011 & 3 & 2 & & 5 & $12,5 \%$ \\
2012 & 4 & 1 & 1 & 6 & $15,0 \%$ \\
2013 & 5 & & & 5 & $12,5 \%$ \\
2014 & 4 & & & 4 & $10,0 \%$ \\
2015 & 1 & & & 1 & $2,5 \%$ \\
2016 & 6 & & & 6 & $15,0 \%$ \\
\hline Total & 29 & 9 & 2 & 40 & $100,0 \%$ \\
\hline
\end{tabular}

Esse período, que engloba 13 anos de produção de conhecimento científico sobre os projetos esportivos mostra um número restrito de produções. Foram encontrados somente 40 produtos nesse período de tempo, mostrando que esta é uma discussão recente que necessita maiores debates e amadurecimento teórico. Torna-se necessário relembrar que foi somente a partir da década de 1990 que os projetos sociais começam a aparecer com mais relevância na sociedade brasileira (ZALUAR, 1994), principalmente pelo crescimento a do Terceiro Setor (SZAZI, 2006), responsável em grande parte pela execução desses projetos.

Apesar de ser uma temática recente considerando o período de tempo de produções científicas sobre projetos esportivos, o esporte é um assunto amplamente estudado, principalmente do âmbito da Educação Física, porém, sem se restringir a ela. Quando se analisa as áreas de conhecimento em que foram produzidas as dissertações e teses é possível verificar que a Educação Física concentra grande parte das produções, 
conforme mostrado na Tabela 2. Entretanto o assunto também é discutido em outras áreas.

Tabela 2. Áreas de conhecimento das dissertações e teses produzidas - Sistematizado pelos autores.

\begin{tabular}{ccc}
\hline $\begin{array}{c}\text { Área de } \\
\text { Conhecimento }\end{array}$ & $\begin{array}{c}\text { Quantidade de dissertações e/ou } \\
\text { teses produzidas em cada área }\end{array}$ & \% total \\
\hline Educação Física & 6 & $54,5 \%$ \\
Psicologia & 2 & $18,2 \%$ \\
Educação & 2 & $18,2 \%$ \\
Medicina & 1 & $9,1 \%$ \\
\hline Total & 11 & $100,0 \%$ \\
\hline
\end{tabular}

Os dados mostram que a discussão sobre os projetos esportivos não fica restrita somente a Educação Física. Investigações em áreas como Educação, Medicina e Psicologia evidenciam que a temática chama atenção de outras áreas do conhecimento, auxiliando na compreensão de que os projetos esportivos têm seu impacto na sociedade.

Ainda analisando a produção de dissertações e teses, a Tabela 3 mostra o ano da defesa, o nome do autor, o título da pesquisa e em qual universidade a pesquisa foi realizada. É possível perceber que existiu uma concentração na produção de pesquisas de mestrado na Universidade Federal do Rio Grande do Sul (UFRGS), com a produção de cinco dissertações, de um total de nove dissertações e duas teses. 
Tabela 3. Relação de autores, títulos e Universidades das dissertações e teses produzidas. Sistematizado pelos autores.

\begin{tabular}{|c|c|c|c|c|}
\hline Ano & Autor & $\begin{array}{l}\text { Dissertação / } \\
\text { Tese }\end{array}$ & Título & Universidade \\
\hline 2006 & Paula Xavier Machado & $\begin{array}{c}\text { Mestrado em } \\
\text { Psicologia do } \\
\text { Desenvolvimento }\end{array}$ & $\begin{array}{l}\text { Impacto e processo de um } \\
\text { projeto de educação pelo esporte } \\
\text { no desenvolvimento infantil }\end{array}$ & UFRGS \\
\hline 2008 & Rodrigo Cavassini & $\begin{array}{l}\text { Mestrado em } \\
\text { Ciências do } \\
\text { Movimento } \\
\text { Humano }\end{array}$ & $\begin{array}{l}\text { Projetos esportivos sociais } \\
\text { voltados para jovens: um estudo } \\
\text { das contribuições do projeto } \\
\text { Navegar de Porto Alegre }\end{array}$ & UFRGS \\
\hline 2008 & $\begin{array}{l}\text { Anelise Lopes } \\
\text { Rodrigues }\end{array}$ & $\begin{array}{l}\text { Mestrado em } \\
\text { Psicologia }\end{array}$ & $\begin{array}{l}\text { A desportivização das políticas } \\
\text { sociais para a juventude: } \\
\text { discurso salvacionista e práticas } \\
\text { compensatórias }\end{array}$ & PUC-RS \\
\hline 2009 & Leandro Forell & $\begin{array}{l}\text { Mestrado em } \\
\text { Ciências do } \\
\text { Movimento } \\
\text { Humano }\end{array}$ & $\begin{array}{l}\text { Trabalho voluntário em projetos } \\
\text { sociais esportivos }\end{array}$ & UFRGS \\
\hline 2009 & $\begin{array}{l}\text { Rodrigo de Araújo } \\
\text { Monteiro }\end{array}$ & $\begin{array}{l}\text { Doutorado em } \\
\text { Medicina Social }\end{array}$ & $\begin{array}{l}\text { Prevenção a violência: o caso } \\
\text { dos projetos socioesportivos nos } \\
\text { subúrbios cariocas }\end{array}$ & UERJ \\
\hline 2010 & Luciana Martins Brauer & $\begin{array}{l}\text { Mestrado em } \\
\text { Ciências do } \\
\text { Movimento } \\
\text { Humano }\end{array}$ & $\begin{array}{l}\text { Projeto social esportivo: impacto } \\
\text { no desempenho motor, na } \\
\text { percepção de competência e na } \\
\text { rotina de atividades infantis dos } \\
\text { participantes }\end{array}$ & UFGRS \\
\hline 2010 & Silvio Sipliano da Silva & $\begin{array}{l}\text { Mestrado em } \\
\text { Educação }\end{array}$ & $\begin{array}{l}\text { A Educação Física escolar } \\
\text { versus projeto social esportivo: } \\
\text { quando os donos da casa perdem } \\
\text { o jogo }\end{array}$ & USP \\
\hline 2011 & Suéllen Barbosa Eiras & $\begin{array}{l}\text { Mestrado em } \\
\text { Educação Física }\end{array}$ & $\begin{array}{l}\text { Significados de um projeto } \\
\text { social esportivo: o caso do } \\
\text { projeto Esporte em Ação - } \\
\text { Núcleo Vila Torres }\end{array}$ & UFPR \\
\hline 2011 & Jones Zarpellon Mazo & $\begin{array}{l}\text { Mestrado em } \\
\text { Ciências do } \\
\text { Movimento } \\
\text { Humano }\end{array}$ & $\begin{array}{l}\text { Os valores no esporte juvenil : } \\
\text { um estudo com jovens } \\
\text { participantes em projetos pró- } \\
\text { sociais no município de Santo } \\
\text { Ângelo, Rio Grande do Sul }\end{array}$ & UFRGS \\
\hline 2012 & $\begin{array}{l}\text { Luiz Felipe Alcântara } \\
\text { Hecktheuer }\end{array}$ & $\begin{array}{l}\text { Doutorado em } \\
\text { Educação }\end{array}$ & $\begin{array}{l}\text { Projetos sociais esportivos: } \\
\text { ensaios sobre uma proliferação } \\
\text { na cidade do Rio Grande - RS }\end{array}$ & FURG \\
\hline 2012 & $\begin{array}{c}\text { Elder Regis Deorato } \\
\text { Marques }\end{array}$ & $\begin{array}{l}\text { Mestrado em } \\
\text { Educação Física }\end{array}$ & $\begin{array}{l}\text { Projetos sociais esportivos: um } \\
\text { estudo das relações entre o } \\
\text { esporte e o autoconceito }\end{array}$ & USP \\
\hline
\end{tabular}


Além da UFRGS concentrar a maior quantidade de pesquisas, o estado do Rio Grande do Sul (RS) também é destaque, sendo que a Pontifícia Universidade Católica do Rio Grande do Sul (PUC-RS) produziu uma dissertação sobre a temática e a Universidade Federal do Rio Grande (FURG), no RS, produziu uma das duas teses de doutorado sobre o tema, totalizando assim 6 dissertações e 1 tese no RS.

Complementando essa análise de distribuição das publicações por universidades, é interessante notar que a região sul do Brasil, que engloba os estados do Rio Grande do Sul (RS), Santa Catarina (SC) e Paraná (PR) concentra $72 \%$ da produção de teses e dissertações sobre projetos esportivos. Além das sete pesquisas do RS, a Universidade Federal do Paraná (UFPR) tem a produção de uma dissertação de mestrado. As outras pesquisas foram produzidas na Universidade de São Paulo (USP), com duas dissertações e na Universidade Estadual do Rio de Janeiro (UERJ), com uma tese.

Ao dar sequência a apresentação dos resultados foram analisadas as instituições as quais os autores e coautores pertencem. Os dados foram agrupados por estados brasileiros, mais o Distrito Federal como mostra a Tabela 4. Entre autores e coautores foram identificados 73 pesquisadores. Mesmo com a repetição de autores em mais de um artigo, esses pesquisadores foram contabilizados somente uma vez.

Os autores que não estavam diretamente ligados a universidades foram contabilizados pela entidade, possivelmente local de trabalho, que estava identificado na publicação. Apesar de a contagem ter sido feita pelo número de autores e coautores é possível que esta mesma representatividade seja refletida na quantidade de artigos. 
Tabela 4. Quantidade de autores e coautores por estados brasileiros - Sistematizado pelos autores

\begin{tabular}{ccc}
\hline Estado & Quantidade de Autores e Coautores & \% Total \\
\hline Rio de Janeiro & 18 & $24,7 \%$ \\
Rio Grande do Sul & 17 & $23,3 \%$ \\
Paraná & 10 & $13,7 \%$ \\
São Paulo & 8 & $11,0 \%$ \\
Minas Gerais & 6 & $8,2 \%$ \\
Distrito Federal & 4 & $5,5 \%$ \\
Santa Catarina & 3 & $4,1 \%$ \\
Goiás & 1 & $1,4 \%$ \\
Bahia & 1 & $1,4 \%$ \\
Ceará & 1 & $1,4 \%$ \\
Sergipe & 1 & $1,4 \%$ \\
Pernambuco & 1 & $1,4 \%$ \\
Roraima & 1 & $1,4 \%$ \\
Estrangeiro & 1 & $1,4 \%$ \\
\hline Total & 73 & $100,0 \%$ \\
\hline
\end{tabular}

Nota-se que existe um predomínio das regiões sul e sudeste nos cinco primeiros lugares da Tabela 4. Pouca representatividade para os estados da região nordeste e somente uma publicação com autoria ou coautoria de pesquisadores da região norte. Somente um autor foi identificado com vínculo em uma universidade estrangeira.

Os dados apresentados nessa tabela refletem a distribuição dos programas de pós-graduação nas regiões do Brasil (SOUZA; MORAES E SILVA; MOREIRA, 2016). Cirani; Campanário e Silva (2015) mostram que somente 4\% do total de cursos de pósgraduação brasileiros estavam na região Norte no ano de 2011 , enquanto 51\% estavam na região Sudeste e $20 \%$ estavam na região sul. Essa distribuição irregular impacta diretamente na produção científica local, uma vez que os cursos de mestrado e doutorado impulsionam a pesquisa, o debate e a publicação de novos conhecimentos.

O analisar a distribuição dos artigos nos estratos do Qualis, é possível perceber uma diversificação, com maior número no estrato B1, correspondendo a 44,8\% dos artigos analisados. Somente três artigos foram publicados em revistas classificadas 
como A2, correspondendo a $10,3 \%$ do material analisado. O estrato B3 não teve nenhuma publicação e os estratos B2 e B4 tiveram 6 publicações cada um deles.

Tabela 5. Quantidade de artigos publicados por estrato Qualis - Sistematizado pelos autores.

\begin{tabular}{ccc}
\hline Extrato Qualis & Quantidade de artigos publicados & \% Total \\
\hline A2 & 3 & $10,3 \%$ \\
B1 & 13 & $44,8 \%$ \\
B2 & 6 & $20,7 \%$ \\
B4 & 6 & $20,7 \%$ \\
Não classificado no Qualis da área & 1 & $3,4 \%$ \\
\hline Total & 29 & $100,0 \%$ \\
\hline
\end{tabular}

A pouca quantidade de publicações nos estratos superiores do Qualis, pode ser compreendida pela quantidade limitada de revistas que alcançam essa classificação. Sampaio (2014) explica que o sistema de qualificação apresenta percentuais rígidos de periódicos que podem estar em cada estrato, limitando a quantidade de revistas que podem ser A1 ou A2.

Entre os artigos analisados, um deles foi publicado em uma revista não classificada na área 21. O artigo analisa a gestão de uma política social, implantada em uma favela do Rio de Janeiro, que envolve parcerias entre Estado, iniciativa privada e comunidade. Coincidentemente, esse artigo é o primeiro registro de publicação na temática de projetos esportivos estudados nesta pesquisa.

As diferentes abordagens do esporte confirmam o seu caráter polissêmico e polimórfico, que pode ser estudado de diferentes ângulos e por diferentes vertentes epistemológicas, conforme já apontaram anteriormente Souza; Moraes e Silva e Moreira (2016). No mapeamento das revistas em que os artigos foram publicados, foram encontradas 12 revistas diferentes. A Revista Brasileira de Ciências do Esporte (RBCE) foi a que apresentou maior quantidade de publicações referentes a projetos esportivos, totalizando 6 artigos, que compreende $20,7 \%$ do material total analisado. Entretanto, as 
outras publicações estão distribuídas de forma equilibrada em outros periódicos. A revista Motricidade e Licere publicaram 4 artigos cada uma, totalizando 27,6\% dos artigos publicados. A Movimento e Revista Brasileira de Futsal e Futebol publicaram 3 artigos cada uma, e a Revista Brasileira de Educação Física e Esporte (RBEFE) e a Salusvita publicaram 2 artigos cada. A tabela 6 apresenta a quantidade de artigos publicados por cada periódico e também o seu escopo de atuação.

Tabela 6. Quantidade de publicações por revista e escopo das revistas. Sistematizado pelos autores.

\begin{tabular}{|c|c|c|c|c|}
\hline Revista & Qualis & Quantidade & \% Total & Escopo \\
\hline $\begin{array}{l}\text { Revista Brasileira de } \\
\text { Ciências do Esporte } \\
\text { (RBCE) }\end{array}$ & B1 & 6 & $20,7 \%$ & Educação Física/Ciências do Esporte \\
\hline Motricidade & B1 & 4 & $13,8 \%$ & $\begin{array}{l}\text { Desporto, psicologia, } \\
\text { desenvolvimento humano e saúde }\end{array}$ \\
\hline Licere & B2 & 4 & $13,8 \%$ & $\begin{array}{c}\text { Caráter multidisciplinar relacionado } \\
\text { a área do Lazer }\end{array}$ \\
\hline Movimento & A2 & 3 & $10,3 \%$ & $\begin{array}{c}\text { Educação Física em interface com as } \\
\text { Ciências Humanas e Sociais }\end{array}$ \\
\hline $\begin{array}{c}\text { Revista Brasileira de } \\
\text { Futsal e Futebol (RBFF) }\end{array}$ & B4 & 3 & $10,3 \%$ & $\begin{array}{c}\text { Futsal, Futebol e a Pedagogia do } \\
\text { Esporte no sentido da aprendizagem, } \\
\text { da iniciação e do alto rendimento no } \\
\text { âmbito do esporte, da educação e da } \\
\text { sociedade }\end{array}$ \\
\hline $\begin{array}{l}\text { Revista Brasileira de } \\
\text { Educação Física e } \\
\text { Esporte (RBEFE) }\end{array}$ & $\mathrm{B} 1$ & 2 & $6,9 \%$ & $\begin{array}{c}\text { Áreas de Educação Física, Esporte e } \\
\text { afins }\end{array}$ \\
\hline Salusvita & B4 & 2 & $6,9 \%$ & Ciências biológicas e da saúde \\
\hline $\begin{array}{l}\text { Ciência \& Saúde } \\
\text { Coletiva }\end{array}$ & B1 & 1 & $3,4 \%$ & Saúde Pública \\
\hline Pensar a Prática & B2 & 1 & $3,4 \%$ & Educação Física \\
\hline $\begin{array}{c}\text { Revista da Associação } \\
\text { Brasileira de Psicologia } \\
\text { Escolar e Educacional } \\
\text { (ABRAPEE) }\end{array}$ & B2 & 1 & $3,4 \%$ & Psicologia Escolar e Educacional \\
\hline $\begin{array}{l}\text { Podium - Sport, Leisure } \\
\text { and Tourism Review }\end{array}$ & B4 & 1 & $3,4 \%$ & $\begin{array}{l}\text { Gestão de organizações esportivas, } \\
\text { de lazer e de turismo, abrangendo } \\
\text { disciplinas da Administração de } \\
\text { Empresas, bem como interconexões } \\
\text { com o Direito, a Economia, a } \\
\text { História, a Sociologia, a } \\
\text { Antropologia e a Educação Física. }\end{array}$ \\
\hline $\begin{array}{c}\text { Revista de Sociologia e } \\
\text { Política }\end{array}$ & $*$ & 1 & $3,4 \%$ & Prática política de agentes sociais \\
\hline Total & & 29 & $100,0 \%$ & \\
\hline
\end{tabular}


Quase a totalidade das revistas em que os artigos sobre projetos esportivos foram publicados são da área da Educação Física e tem seu escopo em alguma das vertentes da área. Como o tema gerador dessa pesquisa são as publicações sobre projetos esportivos pode-se perceber uma predominância nas revistas que apresentam escopo direcionado para as Ciências Sociais e Humanas como a Licere, a Movimento, a Pensar a Prática e a Podium - Sport, Leisure and Tourism Review. O somatório dos artigos publicados nessas revistas corresponde a $45 \%$ do total dos artigos publicados. A RBCE apresenta um escopo amplo, que abarca todas as abordagens e metodologias da Educação Física, sem privilegiar qualquer vertente epistemológica (VAZ; ALMEIDA; BASSANI, 2016).

Nessa amplitude é interessante observar a inserção do tema de projetos esportivos também em revistas com escopo na psicologia educacional e escolar como a Revista da Associação Brasileira de Psicologia Escolar e Educacional e também a vertente das ciências sociais e políticas com a inserção na Revista de Sociologia e Política.

As diferentes inserções do tema de projetos esportivos dentro da área da Educação Física e de outras áreas do conhecimento exige um olhar mais aproximado de cada produção científica analisada nessa pesquisa. Após a Análise de Conteúdo (BARDIN, 1977) as publicações foram categorizadas conforme mostra a tabela 7.

Tabela 7. Quantidade de produção científica nas categorias - Sistematizado pelos autores.

\begin{tabular}{|c|c|c|}
\hline Categorias & Quantidade de produção científica & \% Total \\
\hline Significados e sentidos & 9 & $22,5 \%$ \\
\hline Mudança de comportamento & 8 & $20,0 \%$ \\
\hline Políticas Públicas & 8 & $20,0 \%$ \\
\hline Saúde & 8 & $20,0 \%$ \\
\hline Prática Pedagógica & 3 & $7,5 \%$ \\
\hline Responsabilidade Social & 2 & $5,0 \%$ \\
\hline Gestão & 2 & $5,0 \%$ \\
\hline Total & 40 & $100,0 \%$ \\
\hline
\end{tabular}


A heterogeneidade das possíveis abordagens do tema de projetos esportivos está representada pela grande quantidade de categorias possíveis para englobar os estudos. Entretanto, quatro categorias englobam $82,5 \%$ de todas as publicações, sendo elas: "Significados e Sentidos", "Mudança de Comportamento", "Políticas Públicas" e "Saúde".

A categoria Significados e Percepções, com 9 publicações, investiga de que forma a prática esportiva nos projetos pode contribuir na formação do público alvo dos projetos, e quais os significados que a participação nesses projetos assume para quem deles faz parte. De acordo com Martinez e Mezzadri (2007, p.6), o esporte apresenta vários conceitos e significados para quem o pratica, sendo necessário o entendimento dos significados atribuídos pelos indivíduos, através de pesquisas "que não pretendam ‘encaixar' os fatos em um modelo de análise pronto".

Os alunos, responsáveis pelos alunos e professores, se relacionam de formas diferentes com os projetos. Compreender as nuances desses significados, seja somente para um grupo de indivíduos ou todos os envolvidos, favorece uma visão capaz de implantar projetos condizentes com as expectativas dos beneficiários. Esses artigos foram encontrados nas revistas RBCE com 2 artigos, Licere com 2 artigos, Movimento, RBEFE e Salusvita com publicação de um artigo em cada. Além de ser tema de 2 dissertações de mestrado.

Outra categoria com um grande percentual de publicações é referente as mudanças de comportamentos dos alunos participantes. Nesta categoria estão relacionados estudos sobre aprendizagem e internalização de valores, mudanças no desempenho escolar e qualidade de vida, contribuições no processo de socialização e atitudes sociais. As revistas RBCE, Licere, RBEFE, Salusvita, RBFF e ABRAPEE 
publicaram 1 artigo cada uma nessa categoria. Também foram produzidas 3 dissertações nessa categoria.

A categoria de estudos referentes a Políticas Públicas apresentou 8 publicações, totalizando $20 \%$ do material analisado. Essa categoria abrange a discussão sobre o esporte como um direito, análise de políticas públicas em diferentes localidades, avaliação de políticas públicas em localidades e para públicos específicos. Nessa categoria foram produzidas 2 dissertações de mestrado e 1 tese de doutorado. Foram publicados um artigo em cada uma das seguintes revistas: RBCE, Licere, ABRAPEE, Ciência \& Saúde Coletiva e na revista de Sociologia e Política.

A categoria Saúde engloba diferentes perspectivas relacionadas a capacidades físicas, composição corporal e desenvolvimento motor. A aplicação e validação de testes padronizados são características dos estudos nessa categoria. A revista Motricidade publicou 3 artigos nessa temática, os periódicos RBCE, RBEFE, RBFF publicaram 1 artigo cada uma. Foi produzida 1 dissertação de mestrado e 1 tese de doutorado sobre esta temática.

Outras três categorizações apresentam uma representatividade menor na quantidade de publicações, com 17,5\% do total. A categoria Prática Pedagógica engloba estudos referentes a formação profissional, escolha de conteúdos e formas de intervenção. Os três artigos dessa categoria foram publicados nas revistas RBCE, Pensar a Prática e Motricidade, representando 7,5\% das publicações encontradas nesse mapeamento.

A categoria Responsabilidade Social engloba assuntos relacionados ao terceiro setor, iniciativa privada e trabalho voluntário. Existem duas publicações nessa 
categoria, um artigo publicado na revista Podium - Sport, Leisure and Tourism Review, e o outro refere-se a uma dissertação de mestrado.

A categoria Gestão representa $5 \%$ do material analisado e tem 2 artigos publicados nas revistas Movimento e RBFF, sendo um artigo em cada uma. Essa categoria engloba análise sobre indicadores de frequência, adesão, rotatividade, número de alunos e a gestão desses indicadores.

Após compreender quais os focos específicos das produções científicas, é possível aprofundar ainda mais o olhar e analisar as técnicas de pesquisa utilizadas pelos artigos, dissertações e teses estudadas nessa investigação. A Tabela 8 mostra todas as técnicas de pesquisa utilizadas, sendo que testes validados, entrevistas, análise documental e questionários foram os mais utilizados nos materiais analisados.

Tabela 8. Técnicas de pesquisa utilizadas - Sistematizado pelos autores.

\begin{tabular}{cc}
\hline Técnicas utilizadas & Quantidades \\
\hline Testes validados & 12 \\
Entrevistas & 9 \\
Análise documental & 9 \\
Questionários & 5 \\
Observação participante & 4 \\
Revisão Bibliográfica & 3 \\
Observação etnográfica & 3 \\
Análise de Discurso & 2 \\
\hline Total & 47 \\
\hline
\end{tabular}

É interessante observar que existe uma divisão entre técnicas quantitativas e qualitativas. Os procedimentos apresentados podem indicar duas abordagens distintas para as pesquisas científicas sobre projetos esportivos, tanto na área das ciências biológicas e da saúde como na das ciências humanas e sociais. Entretanto, atualmente não é possível mais dizer que os métodos qualitativos são exclusivos das ciências humanas e sociais. Assim como não é possível afirmar que os métodos quantitativos são exclusividade das ciências biológicas e da saúde (TURATO, 2005). 
Ao observar atentamente as técnicas de pesquisa utilizadas é possível relacionar essas informações com as categorias "Saúde", "Mudança de Comportamento" e a de "Significados e sentidos”. Um grande número de utilização de testes validados para avaliação de diferentes capacidades está relacionado aos estudos que tinham por objetivos avaliar desenvolvimento motor, aptidão física, desenvolvimento psicológico, aprendizagem de valores, entre outros. A grande utilização da técnica da entrevista está diretamente relacionada aos estudos sobre "Significados e sentidos". Para Gil (2008) a utilização da técnica da entrevista é ideal para coleta de informações sobre como as pessoas se sentem, o que sabem, o que fazem ou pretendem fazer sobre determinado assunto. Essa é a técnica de coleta de dados mais utilizada nas ciências sociais e possibilita a uma análise mais aprofundada sobre o comportamento humano.

\section{Considerações Finais}

As discussões sobre a utilização do esporte como ferramenta de educação e transformação social no Brasil estão presentes nas agendas de diferentes áreas, passando pela política, educação e até segurança (THOMASSIN, 2014). O levantamento do que foi produzido de conhecimento científico sobre projetos esportivos contribui para aprofundar as discussões sobre essa temática.

A análise de 29 artigos, 9 dissertações e 2 teses demonstrou que é uma área recente, com publicações somente a partir de 2003. Caracteriza-se assim como um fórum iniciante, com pouca bagagem de discussões, em que o conhecimento produzido precisa ser discutido e reconstruído para se que possa ter maior solidez teórica.

A distribuição geográfica das produções científicas é centralizada nas regiões Sul e Sudeste, com destaque para o estado do Rio Grande do Sul na produção de 
dissertações de mestrado e tese de doutorado sobre projetos esportivos. Na distribuição dos periódicos que publicaram artigos sobre a temática é concentrada nos estratos B1 e B2 do Qualis, com poucos artigos no estrato A2. Os artigos foram publicados em 12 revistas diferentes, sendo que a RBCE concentrou o maior número de artigos publicados sobre projetos esportivos.

Foi possível analisar uma diversidade epistemológica grande na análise das publicações. As produções foram classificadas em 7 categorias com destaque para significados e percepções, saúde, políticas públicas e mudanças de comportamento. Essa diversidade epistemológica deixa a produção de conhecimento pulverizada, já que um estudo de um subtema não se relaciona e nem oferece discussão a outro estudo de subtema diferente.

A multiplicidade de categorias também aparece ao se analisar as áreas de conhecimento que estão ligados os programas de pós-graduação em que foram produzidas as dissertações e teses que apresentaram projetos esportivos como tema. A Educação Física se apresentou como centro da discussão, porém com outras áreas como Psicologia, Educação e Medicina também estão produzindo sobre projetos esportivos.

Essa diversidade de olhares sobre o mesmo tema garante diferentes abordagens e focos em áreas de conhecimento diferentes como no campo das ciências da saúde e biológicas e também ciências sociais e humanas. O caminhar por diferentes áreas também se reflete no levantamento das técnicas de pesquisa utilizadas nos artigos, dissertações e teses estudados.

A realização do mapeamento da produção científica na área de projetos esportivos permitiu o desenho de um quadro inicial sobre a temática. Esse estudo não esgotou todas as possibilidades de análise e interpretação do conhecimento científico 
produzido sobre projetos esportivos, mas serve como referencial inicial para compreensão do que vem sendo discutido no campo acadêmico sobre esse tema. Esse campo ainda é muito vasto para pesquisa e debates superando a superficialidade da pureza e bondade do esporte.

\section{REFERÊNCIAS}

BAILEY, R. Evaluating the relationship between physical education, sport and social inclusion. Educational Review, Londres v. 57, n. 1, pp. 71-90, 2005.

BARDIN, L. Análise de conteúdo. Lisboa: Edições 70, 1977.

BENTO, J. Desporto: discurso e substância. Belo Horizonte: Campo das Letras. 2013.

CIRANI, C. B. S.; CAMPANARIO, M. de A.; SILVA, H. H. M. da. A evolução do ensino da pós-graduação senso estrito no Brasil: análise exploratória e proposições para pesquisa. Revista da Avaliação da Educação Superior, Campinas, v. 20, n. 1, p. 163 $187,2015$.

COAKLEY, J. Sports in Society: Issues and Controversies. 11. ed. New York: McGran-Hill Education. 2014.

COAKLEY, J. Sports in Society: Issues and Controversies. 11. ed. New York: McGran-Hill Education. 2015a.

COAKLEY, J. Assessing the sociology of sport: on cultural sensibilities and the great sport mith. International Review for the Sociology of Sport, Londres, v. 50, p. 402406, $2015 b$.

COALTER, F. Sport for development: What game are we playing? New York: Routledge, 2013.

CORRÊA, A. J. et al. O esporte brasileiro entre dilemas epistemológicos: da acusação à busca por absolvição. Revista Brasileira de Ciência e Movimento, Brasília, v. 22, n. 3, p. 118-125, 2014.

GIL, A. C. Métodos e técnicas de pesquisa social. Editora Atlas SA, 2008.

KIDD, B. A new social movement: Sport for development and peace. Sport in society, Londres, v. 11, n. 4, p. 370-380, 2008.

LAKATOS, E. M.; MARCONI, M. de A. Fundamentos de pesquisa metodológica científica. São Paulo: Atlas, 2003. 
LEVERMORE, R. Sport: a new engine for development? Progress in Development Studies, Liverpool, v. 8, n. 2, p. 183-190, 2008.

MARTINES, I. C.; MEZZADRI, F. M. Os modelos de análise sociológica e a elaboração de políticas públicas: a necessidade de novos olhares para o esporte. In: CONGRESSO BRASILEIRO DE CIÊNCIAS DO ESPORTE, XV, 2007, Centro de Convenções de Pernambuco. Anais... Pernambuco, 2007. CD-ROM.

MORAES, P. M. et al. O Programa Segundo Tempo na região Centro-Oeste: continuidade e estrutura burocrática do esporte nos municípios. Revista Brasileira de Ciência e Movimento, Brasília, v. 25, n. 1, 2017.

PAES, R. R. Pedagogia do esporte: contextos, evolução e perspectivas. Revista Brasileira de Educação Física e Esporte, São Paulo, v. 20, n. 5, p. 171, 2006.

REVERDITO, R. S. et al. O Programa Segundo Tempo (PST) em municípios brasileiros: indicadores de resultado no macrossistema. Journal of Physical Education, Maringá, v. 27, n. 1, p. 2754, 2016.

ROMANOWSKI, J. P.; ENS, R. T. As pesquisas denominadas do tipo "Estado da Arte" em Educação. Revista Diálogo Educacional, Curitiba, v. 6, n. 19, p. 37-50. 2006.

SAMPAIO, T. M. V. Desafios e perspectivas para a divulgação da pesquisa em Educação Física: um processo em construção. Revista Brasileira de Ciência do Esporte, Campinas, v. 36, n. 4, p. 733-739, 2014.

SÁ-SILVA, J. R.; ALMEIDA, C. D. de; GUINDANE, J. F. Pesquisa Documental: pistas teóricas e metodológicas. Revista Brasileira de História \& Ciências Sociais, São Leopoldo, ano I, n. I, 2009. Disponível em: <https://www.rbhcs.com/rbhcs/ article/view/6/0> Acesso em: 01 de fev. de 2016.

SOUZA, D. L., CASTRO, S. B. E., MEZZADRI, F. M. Facilitadores e barreiras para a implantação e participação em projetos sociais que envolvem atividades esportivas: os casos dos projetos Vila na Escola e Esporte Ativo. Revista Brasileira de Educação Física e Esporte, São Paulo, v. 26, n. 3, p. 419-430, 2012.

SOUZA, D. L.; MORAES E SILVA, M; MOREIRA, T. S. et al. O perfil da produção científica online em português relacionada às modalidades olímpicas e paralímpicas. Movimento, Porto Alegre, v. 22, n. 4, p. 1105-1120, 2016.

STIGGER, M. P; THOMASSIM, L. E. Entre o "serve" e o "significa": uma análise sobre perspectivas atribuídas ao esporte em projetos sociais. Licere, Belo Horizonte, v. 16, n. 2, 2013.

SZAZI, E. Terceiro Setor: regulação no Brasil. 4. ed. São Paulo: Petrópolis, 2006.

THOMASSIN, L. E. Oferta de projetos sociais e a ação das crianças: a construção de uma experiência de infância "público-alvo. Civitas-Revista de Ciências Sociais, Porto Alegre v. 13, n. 2, p. 364-380, 2014. 
TURATO, E. R. Métodos qualitativos e quantitativos na área da saúde: definições, diferenças e seus objetos de pesquisa. Revista de Saúde Pública, São Paulo, v. 39, n. 3 , p. 507-514, 2005.

VAZ, A. F.; ALMEIDA, F. Q. de; BASSANI, J. J. Foco e escopo: o que é um artigo em Educação Física? Revista Brasileira de Ciências do Esporte, Campinas, v. 38, n. 2, p. 105-106, 2016. Editorial.

ZALUAR, A. Cidadãos não vão ao Paraíso. São Paulo: Escuta, 1994.

\section{Endereço dos Autores:}

Ana Elisa Guginski Caron

Departamento de Educação Física - UFPR

Rua Coração de Maria, 92 - Jardim Botânico

Curitiba - PR - 80.050-540

Endereço Eletrônico: anaecaron@gmail.com

Wanderley Marchi Junior

Departamento de Educação Física - UFPR

Rua Coração de Maria, 92 - Jardim Botânico

Curitiba - PR - 80.050-540

Endereço Eletrônico: wmarchijr@gmail.com

Marcelo Moraes e Silva

Departamento de Educação Física - UFPR

Rua Coração de Maria, 92 Jardim Botânico

Curitiba - PR - 80.050-540

Endereço Eletrônico: moraes_marc@yahoo.com.br 